\title{
Neuromuscular Choristoma of the External Peroneal Nerve: A Case Report and Review of the Literature
}

\author{
Sergio Hortelano*, Marta Salom, Elena Fernandez, and M Angeles Blasco \\ Department of Pediatric Orthopedic Surgery, La Fe University Hospital, Valencia, Spain
}

*Corresponding author: Sergio Hortelano, Department of Pediatric Orthopedic Surgery, La Fe University Hospital, Fernando Abril Martorell 106, Valencia, Spain, Tel: +34 609233874; E-mail: sergio_horte5@hotmail.com

Received: 06 Jan, 2020 | Accepted: 11 Feb, 2020 | Published: 17 Feb, 2020

Citation: Hortelano S, Salom M, Fernandez E, Blasco MA (2020) Neuromuscular Choristoma of the External Peroneal Nerve: A Case Report and Review of the Literature. J Surg Open Access 6(2): dx.doi.org/10.16966/2470-0991.208

Copyright: (c) Hortelano S, et al. This is an open-access article distributed under the terms of the Creative Commons Attribution License, which permits unrestricted use, distribution, and reproduction in any medium, provided the original author and source are credited.

\begin{abstract}
Case: We report the case of a 4-day-old male infant with a Choristoma of the External peroneal nerve. In the second week of life, he developed an acute peroneal nerve neuropathy. An open biopsy was needed to confirm the diagnosis and decompression of the External peroneal nerve were performed. After 3.5 years of follow-up, the child has complete passive ankle motion but not active dorsal flexion. The US reveals that the child's normal growth is related to small tumor growth.

Conclusion: Choristomas are infrequent benign tumors that arise from the peripheral nerves formed by mature skeletal muscle elements mixed with mature neural elements. They present as solitary lesions and are located in cranial nerves, spinal cord and large peripheral nerves such as median nerve, brachial plexus and sciatic nerve. In this case report, we describe the first case reported, as far as we know, of a Choristoma arising from the External peroneal nerve in a newborn, focusing on the difficulties on diagnosis and treatment and we have carried out a systematic review of the literature.
\end{abstract}

Keywords: Hamartoma; Neuromuscular choristoma; Benign triton tumour; Peroneal tumour

\section{Introduction}

Neuromuscular choristoma, also known as neuromuscular hamartoma or benign triton tumor, is an extremely rare tumor composed of well-differentiated skeletal muscle and matures nerve fibers. These lesions usually appear in the first decade of life with no male/female preponderance and have been reported to be associated with cranial nerve trunks (like trigeminal nerve), brachial plexus, median nerve and sciatic nerve $[1,2]$.

To our knowledge, our case is the $16^{\text {th }}$ case of sciatic nerve neuromuscular choristoma that can be found in the medical literature. This is the first case that affects the External peroneal Nerve and it is the youngest patient registered so far in the literature.

The histogenesis of neuromuscular hamartoma remains a controversial issue. We report a new case of this rare tumor, and we also review the literature of all such cases [3].

\section{Case Report}

A 4-day-old male was referred to our hospital from another center, with a suspected superior tibiofibular joint dislocation and a growth of the soft tissues on the lateral aspect of the left knee since birth (Figure 1A). The infant's physical examination was normal; in addition, there was no pertinent family history.
The radiographic study showed an increase in the proximal tibiofibular distance (Figure 1B). The ultrasound study demonstrated a hypoechoic mass of $1.5 \mathrm{~cm}$ surrounding the left fibula head located in the subcutaneous cellular tissue without affecting the bone or cartilage of the fibula.

The Magnetic Resonance Images (MRI) described a nodular lesion $10.4 \times 7 \times 18.7 \mathrm{~mm}$ in diameter that was located behind the subcutaneous tissue that was not affected, and in contact with the fibular head and soleus muscle. The mass presented a moderate and homogeneous uptake of contrast and showed a fusiform morphology along the path of the peroneal nerve (Figures $2 \mathrm{~A}$ and $2 \mathrm{~B}$ ).

A Percutaneous ultrasound-guided biopsy was done, resulting in non-specific muscle tissue.

In the second week of life, the child developed a sudden loss of ankle dorsal flexion and a foot drop, we have not noted active dorsal flexion at birth. Electromyography was performed at three weeks of birth, showing evidence of left peroneal nerve neuropathy with active denervation and absence of potential independent muscles of the left peroneal nerve (peroneus longus and tibialis anterior muscles).

This circumstance and the need for a firm diagnosis drove us to operate on the patient. An incision over the fibular was performed at four weeks of birth from the tip of the fibular head and extended posterolaterally in order to visualize the External peroneal nerve 


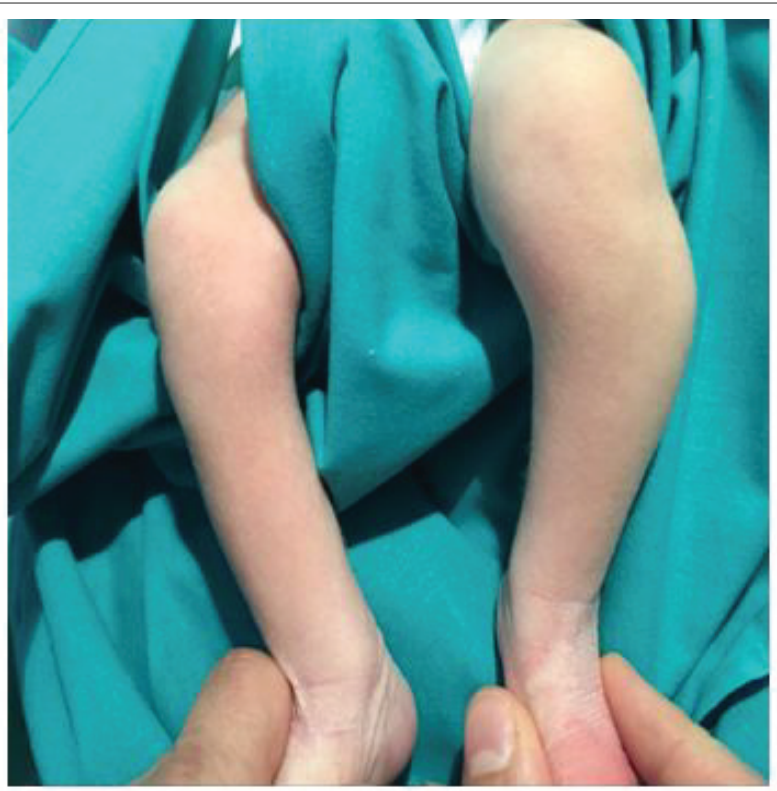

Figure 1A: Photograph of the child aged 4 days, where we can appreciate a mass located proximal and lateral on his left leg.

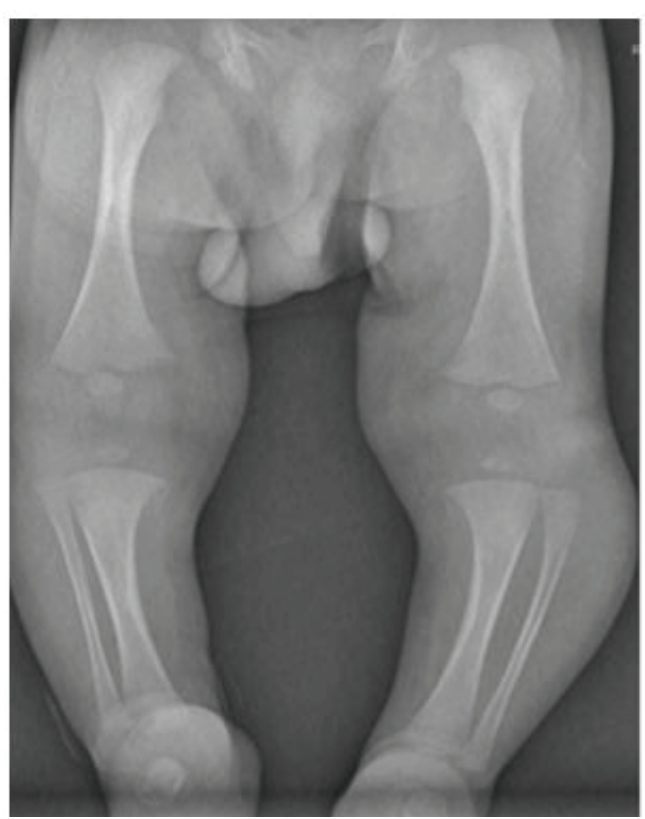

Figure 1B: Antero-posterior (AP) radiograph showed increased thickness in the left leg associated with an increase in the proximal tibiofibular distance.

bifurcation. The peroneal nerve was notably hypertrophic, firm and bulbous. An intraoperative biopsy was conducted resulting in the same findings, non-specific muscle tissue without signs of malignancy. This led us to perform a decompression of the peroneal nerve and an open biopsy from this nerve (Figure 3). Post-operatively the patient had no new neurological deficits.

The biopsy specimens were embedded in paraffin and sections were stained with hematoxylin and eosin and trichrome. Immunohistochemistry was also performed.
Pathological examination showed small nodules and fascicles which were composed of well-developed striated muscle fibers and expressed Desmin, and normal nerve bundles confirmed by S-100 protein and neurofilament in a fibrous stroma (Figures $4 \mathrm{~A}-4 \mathrm{E}$ ).

The two basic components of nerve fibers and muscle fibers were indivisibly intermingled respectively. No cell atypia or pleomorphism and no primitive undifferentiated cells that suggested malignancy was observed in that tissue sample.

After 3.5 years of follow-up, the child has complete passive ankle motion, not active dorsal flexion is present, but the child doesn't have a foot drop. He is able to walk without support but an antiequinus orthosis is used at nights. The US reveals a small growth of the tumor-related with the child's normal growth. No evidence of undergrowth in foot appears at that moment. We suspect that Choristoma may be present in the mother's womb because the lesion was detected at 4 days of life.

\section{Discussion and Conclusion}

The Choristoma or benign tumor triton is a tumor-like malformation consisting of a random proliferation of mature histological elements. It appears as an irregular proliferation of nerve fibers intermingled with fibers of mature muscle tissue in the course of the affected nerve [4,5].

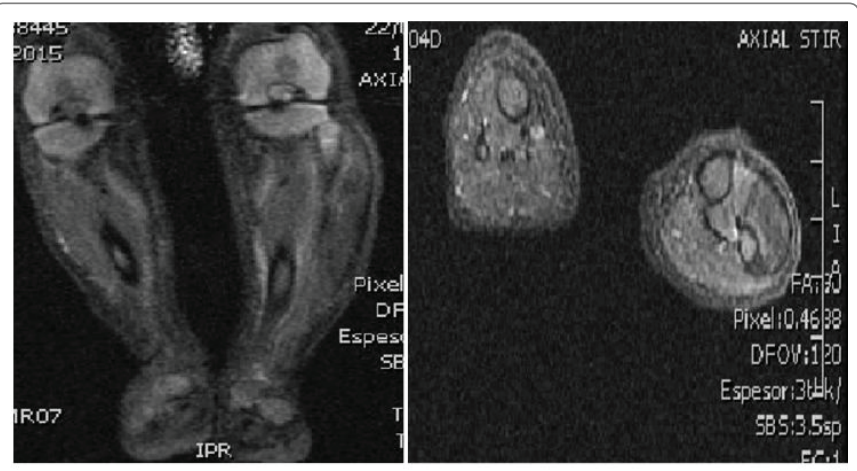

Figure 2A and 2B: An Axial and B coronal MR images where we can observe a tumor with fusiform morphology that follows the path of the external peroneal nerve without affecting de fibula.

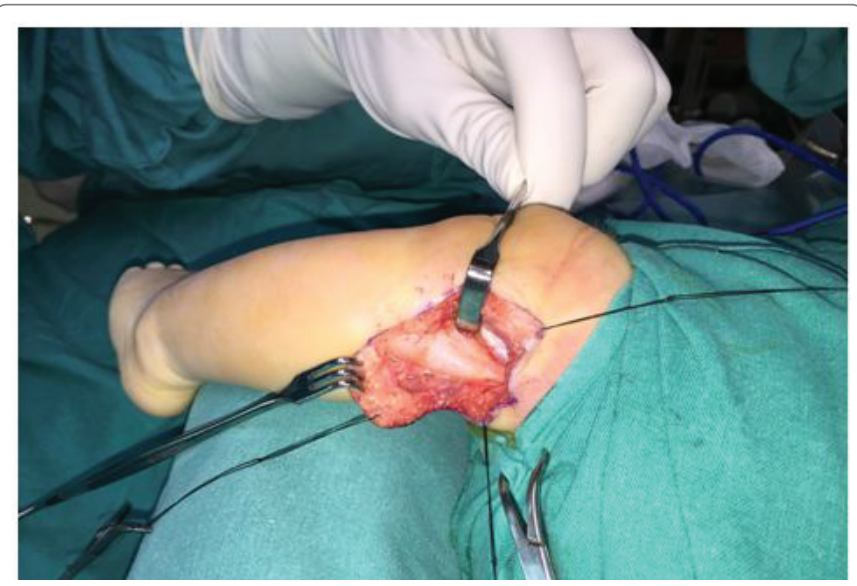

Figure 3: A longitudinal incision over the fibular head was performed. We can see a thickening of about $4 \mathrm{~cm}$ on the path of the external peroneal nerve. 


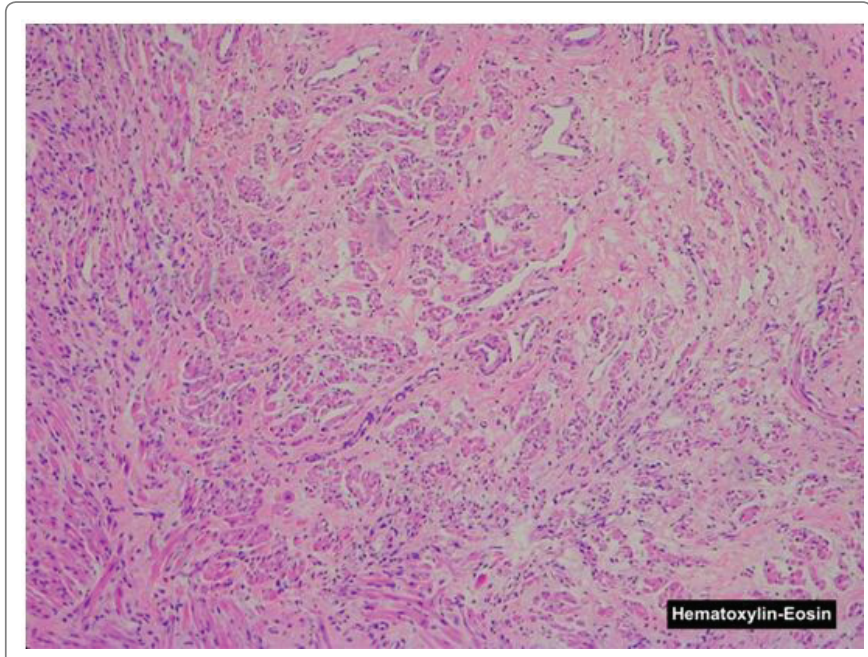

Figure 4A: The nodule is composed of nerve fibers and striated muscle fibers (Hematoxylin and eosin).

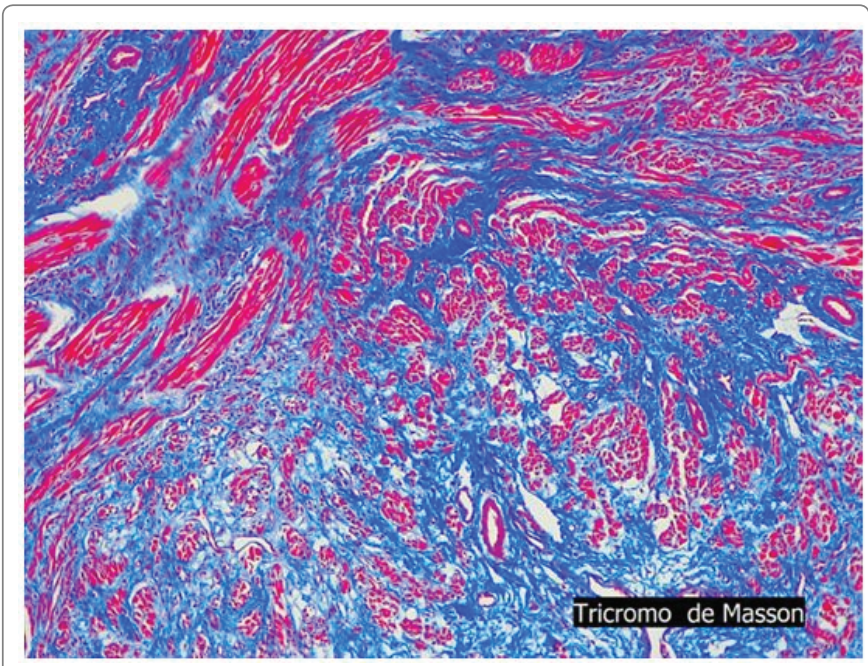

Figure 4B: Neuromuscular choristoma shows nerve fibers and muscle fibers that were individually scattered in a collagenous stroma.

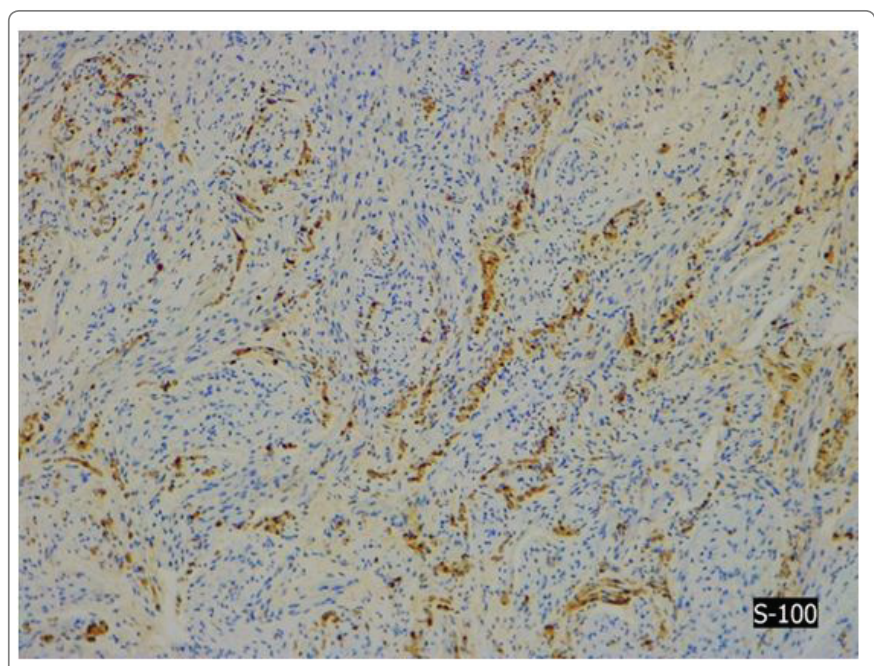

Figure 4C: Immunostaining for S-100.

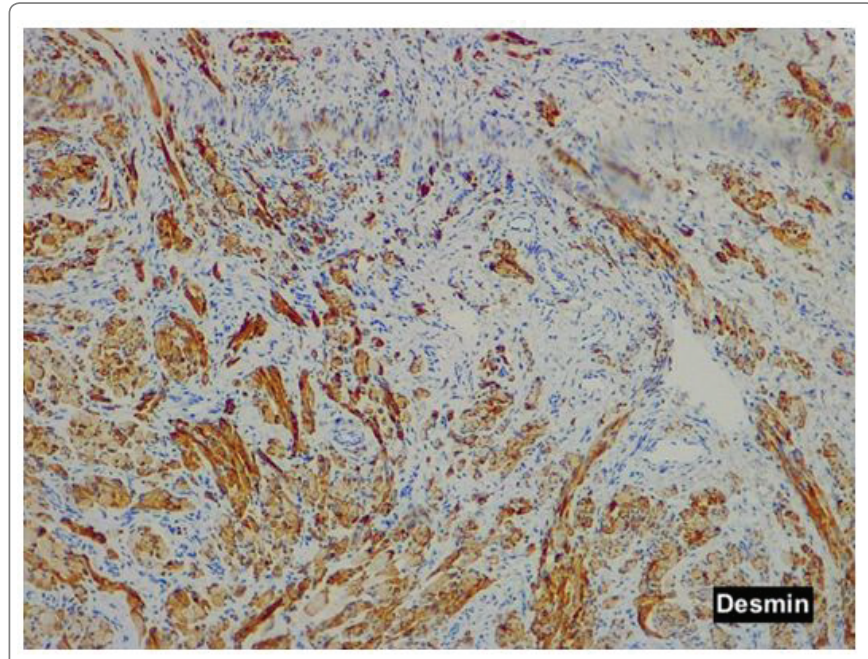

Figure 4D: Desmin shows positive nerve fibers in the nodule.

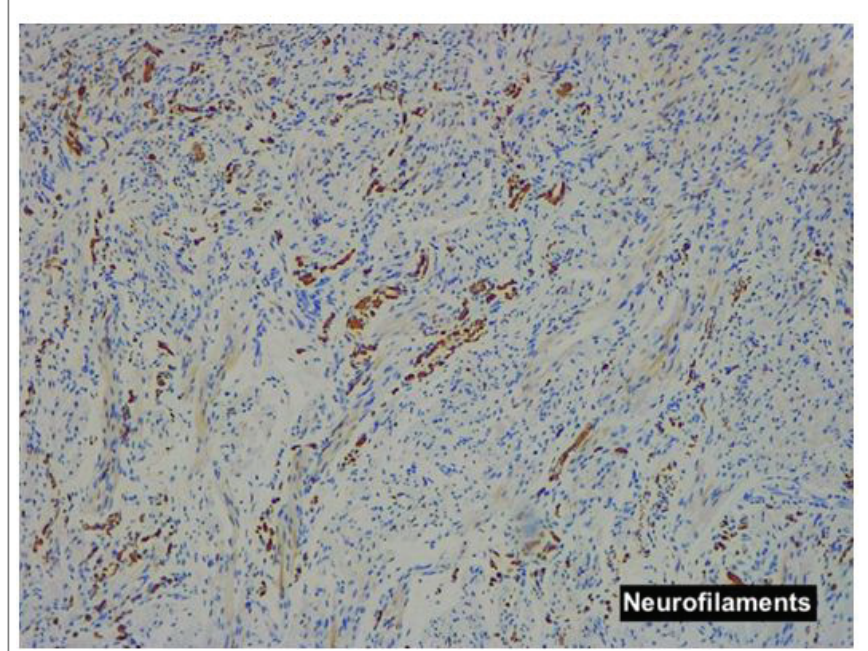

Figure 4E: Neurofilaments show normal nerve bundles.

These tumors usually involve large nerves such as the brachial plexus [6] the median nerve, the sciatic nerve, although several cases involve the spinal cord space, the skin and the trigeminal nerve. To our knowledge, this is the $16^{\text {th }}$ reported case of sciatic nerve Choristoma, the first benign triton tumor that involves the external peroneal nerve and it is the youngest patient registered in the literature. Park JE, et al. [7] collects in his work all the cases in the literature, we must add our case and it is the most rapidly diagnosed choristoma in the literature.

Most cases occur in childhood. There are 3 adult patients and 13 pediatric patients (age range: $0-18$ years). There are six female and ten male patients, and six cases of left side neuromuscular choristomas, nine cases of the right size and one case not reported $[8,9]$.

The pathogenesis of this tumor is not well known and the histogenesis remains a controversial issue. Several theories exist that propose the incorporation of limb mesenchyme within the nerve sheaths of developing nerves, muscle entrapment in developing nerves, neuroectoderm giving rise to metaplastic mesenchymal components, and even neural induction on surrounding mesenchyme into skeletal muscle. 
Table 1: Cases of neuromuscular hamartomas affecting the sciatic nerve reported in the literature.

\begin{tabular}{|c|c|c|c|c|c|c|}
\hline Case & Age & Sex & Localization & Symptoms & Intervention & References \\
\hline Present case & 0 & Male & CPE & Loss dorsiflexion ankle & $\begin{array}{l}\text { Open biopsy+ } \\
\text { Decompression }\end{array}$ & \\
\hline 2 & 1 & Male & Sciatic Nerve & $\begin{array}{l}\text { Posterior thigh palpable firm subcutaneous } \\
\text { lump at birth }\end{array}$ & Partial resection & Louhimo I, et al. [8] \\
\hline 3 & 2 & Female & Sciatic Nerve & Right sciatic distribution weakness & Partial resection & Markel SF, et al. [4] \\
\hline 4 & 4 & Female & Sciatic Nerve & Left leg cavovarus foot deformity and spasticity & Open biopsy & Bonneau R, et al. [12] \\
\hline 5 & 5 & Female & Sciatic Nerve & $\begin{array}{l}\text { Right sciatic distribution weakness, cavovarus } \\
\text { foot }\end{array}$ & Open biopsy & Hebert-Blouin MN, et al. [7] \\
\hline 6 & 8 & Male & Sciatic Nerve & $\begin{array}{l}\text { Painless progressive right cavovarus foot } \\
\text { deformity }\end{array}$ & Open biopsy & Bassett GS, et al. [2] \\
\hline 7 & 11 & Male & Sciatic Nerve & $\begin{array}{l}\text { Progressive right leg pain and weakness, } \\
\text { hammertoes }\end{array}$ & Open biopsy & Lam S, et al. [3] \\
\hline 8 & 18 & Male & Sciatic Nerve & $\begin{array}{l}\text { Pain, weakness and sensory disturbance in the } \\
\text { right sciatic distribution }\end{array}$ & Open biopsy & Orlandi E, et al. [13] \\
\hline 9 & 42 & Male & Sciatic Nerve & $\begin{array}{l}\text { Deterioration of leg function, leg pain and } \\
\text { congenital hip dysplasia }\end{array}$ & CT-guided biopsy & Hebert-Blouin MN, et al. [7] \\
\hline 10 & 68 & Female & Sciatic Nerve & $\begin{array}{l}\text { Cavovarus foot deformity, atrophy, weakness } \\
\text { and congenital hip dysplasia }\end{array}$ & None & Hébert-Blouin MN, et al. [14] \\
\hline
\end{tabular}

Most cases of neuromuscular hamartoma occur in childhood and typically show a relatively benign clinical course throughout life (Table 1). Patients can simply have the presence of a palpable subcutaneous mass, may have pain, muscle atrophy, limb differences based on the length of a member relative to the other, deformities, such as cavo-varus foot, or associate even developmental dysplasia of the hip. In our case, on the four days of life, the patient presented with a mass in the peroneal head and a few days later a loss of foot dorsiflexion.

MRI is an essential test to approach the diagnosis of this pathological image, but a biopsy is necessary in order to make a definitive diagnosis of neuromuscular hamartoma. It is not easy to make the diagnosis by guided percutaneous biopsy and almost impossible to get the diagnosis by intraoperative biopsy. In fact, we performed two percutaneous biopsies without reaching a conclusive diagnosis.

It seems that there is a clear relationship between performing biopsies in the choristomas and the appearance of fibromatosis. In our case, despite performing several biopsies due to the difficulty of extracting a good sample due to being such a small child, we have not had for the moment any recurrence of fibromatosis in the scar or in the biopsy path. [10-15], It seems that evidence supports a no-touch approach to Neuromuscular Choristomas.

Microscopically, these lesions are composed of well-differentiated skeletal muscle and mature nerve fibers.

With respect to which is the best treatment of these tumors, there is no evidence in the literature about the best surgical technique to apply in these cases. We need to consider the benefits that a total resection of the nerve could achieve as opposed to the neurological deficits that would generate in these patients throughout their lives [16].

Some authors have described discrete lesions arising from the nerve that was resectable without a new neurologic deficit [17]. Other reports range from biopsy only [18-20], attempted resection [4], amputation $[4,21]$, while others undertook complete resection of the involved nerve with nerve grafting and assumed postoperative paralysis of the affected limb [16].
In our case, we did a decompression of the peroneal muscle and peroneal nerve but excision was not performed. The child has developed favorably, don't have a foot drop but don't have a positive active ankle dorsal flexion; the mass has increased slightly in size but in proportion to the growth of the baby.

At present, the child is 3.5 years old and is able to walk without external help, and he is wearing a nocturnal anti-equinus splint. The ankle passive mobility is complete although there is a lack of complete active dorsiflexion.

The study of these tumors has shown that they have a benign behavior over the years. Although resection is curative, a neurological deficit is guaranteed. In some cases, biopsy or incomplete excision resulted in the improvement of symptoms and the progressive decrease in the size of tumors. We think that the appropriate treatment should be individualized. If Neuromuscular Choristoma is suspected based on MRI findings, biopsy should not be taken to avoid aggressive fibromatosis.

\section{Conflicts of Interest}

All the authors declare that they have no conflicts of interest.

\section{Source of Funding}

This study has not received any funding.

\section{Ethical Approval}

This article does not contain any studies with human participants or animals performed by any of the authors. Informed consent was obtained from the patient included in the study.

\section{References}

1. Lam S, Grandhi R, Wong R, Hamilton R, Greene S (2013) Neuromuscular hamartoma of the sciatic nerve: Case report and review of the literature. Surg Neurol Int 4: 8.

2. Castro DE, Raghuram K, Phillips CD (2005) Benign triton tumor of the trigeminal nerve. AJNR Am J Neuroradiol 26: 967-969. 
3. Kim SY, Kwon HP, Kwak KD, Ahn KB (2005) Neuromuscular Choristoma of the sciatic nerve-A case report. Korean J Pathol 39: 192-196.

4. Markel SF, Enzinger FM (1982) Neuromuscular hamartoma--a benign "triton tumor" composed of mature neural and striated muscle elements. Cancer 49: 140-144.

5. Van Dorpe J, Sciot R, De Vos R, Uyttebroeck A, Stas M, et al. (1997) Neuromuscular choristoma (hamartoma) with smooth and striated muscle component: case report with immunohistochemical and ultrastructural analysis. Am J Surg Pathol 21: 1090-1095.

6. Goepel U, Torner F, Soldado F (2017) Neuromuscular choriostoma of brachial plexus in a boy: A case report. J Hand Surg Eur 42: 531-532.

7. Park JE (2019) Long-term natural history of a neuromuscular choristoma of the sciatic nerve: a case report and literature review. Clin Imaging 55: 18-22.

8. Bonneau R, Brochu P (1983) Neuromuscular choristoma. A clinicopathologic study of two cases. Am J Surg Pathol 7: 521-528.

9. Orlandi E (1895) Sopra un caso di rabdomioma del nervoischiatico. Arch Sci Med 19: 113-137.

10. Hébert-Blouin MN, Amrami KK, Spinner RJ (2013) Addendum: Evidence supports a "no-touch" approach to neuromuscular choristoma. J Neurosurg 119: 252-254.

11. O'Brien TG, Spinner RJ, Boon AJ (2016) Neuromuscular choristoma presenting with unilateral limb hypoplasia in a 3-year-old boy. Muscle Nerve 54: 797-801.

12. Carter JM, Howe BM, Hawse JR, Giannini C, Spinner RJ, et al. (2016) CTNNB1 Mutations and Estrogen Receptor Expression in Neuromuscular Choristoma and its Associated Fibromatosis. AM J Surg Pathol 40: 1368-1374.
13. Broski SM, Howe BM, Spinner RJ, Amrami KK (2017) Fibromatosis Associated with Neuromuscular Choristoma: Evaluation by FDG PET/CT. Clin Nucl Med 42: e168-e170.

14. Stone JJ, Prasad NK, Laumonerie P, Howe BM, Amrami KK, et al. (2018) Recurrent desmoid-type fibromatosis associated with underlying neuromuscular choristoma. J Neurosurg 131: 175-183.

15. Maldonado AA, Spinner RJ, Broski SM, Stone JJ, Howe BM, et al. (2020) Neuromuscular choristoma-associated desmoid-type fibromatosis: Establishing a nerve territory concept. Acta Neurochir (Wien).

16. Awasthi D, Kline DG, Beckman EN (1991) Neuromuscular hamartoma (benign "triton" tumor) of the brachial plexus. J Neurosurg 75: 795797.

17. Louhimo I, Rapola J (1972) Intraneural muscular hamartoma: report of two cases in small children. J Pediatr Surg 7: 696-699.

18. Bassett GS, Monforte-Munoz H, Mitchell WG, Rowland JM (1997) Cavus deformity of the foot secondary to a neuromuscular choristoma (hamartoma) of the sciatic nerve. A case report. J Bone Joint Surg Am 79: 1398-1401.

19. Hebert-Blouin MN, Scheithauer BW, Amrami KK, Durham SR, Spinner RJ (2012) Fibromatosis: a potential sequela of neuromuscular choristoma. J Neurosurg 116: 399-408.

20. Maher CO, Spinner RJ, Giannini C, Scheithauer BW, Crum BA (2002) Neuromuscular choristoma of the sciatic nerve. Case report. J Neurosurg 96: 1123-1126.

21. Mitchell A, Scheithauer BW, Ostertag H, Sepehrnia A, Sav A (1995) Neuromuscular choristoma. Am J Clin Pathol 103: 460-465. 